\title{
Percutaneous Mitral Valve Repair with the MitraClip System in the Current Clinical Practice
}

\author{
Sergio Sorrentino, Alessandra Berardini *, Giovanni Statuto $\mathbb{(})$, Andrea Angeletti, Giulia Massaro $\mathbb{D}$, \\ Claudio Capobianco, Giuseppe Pio Piemontese, Alberto Spadotto (), Sebastiano Toniolo (ㅁ), \\ Angelo Giuseppe Caponetti, Raffaello Ditaranto, Vanda Parisi $\mathbb{B}^{0}$, Matteo Minnucci, Valentina Ferrara, \\ Nazzareno Galiè and Elena Biagini
}

check for updates

Citation: Sorrentino, S.; Berardini, A.; Statuto, G.; Angeletti, A.; Massaro, G.; Capobianco, C.; Piemontese, G.P.; Spadotto, A.; Toniolo, S.; Caponetti, A.G.; et al. Percutaneous Mitral Valve Repair with the MitraClip System in the Current Clinical Practice. Hearts 2021, 2, 74-86. https://doi.org/ $10.3390 /$ hearts 2010007

Received: 17 November 2020

Accepted: 18 January 2021

Published: 22 January 2021

Publisher's Note: MDPI stays neutra with regard to jurisdictional claims in published maps and institutional affiliations.

Copyright: (c) 2021 by the authors. Licensee MDPI, Basel, Switzerland This article is an open access article distributed under the terms and conditions of the Creative Commons Attribution (CC BY) license (https:// creativecommons.org/licenses/by/ $4.0 /)$.
Cardiology, Department of Experimental, Diagnostic and Specialty Medicine (DIMES), Alma Mater Studiorum, University of Bologna, 40138 Bologna, Italy; sergio.sorrentino@studio.unibo.it (S.S.); giovanni.statuto@studio.unibo.it (G.S.); andrea.angeletti8@unibo.it (A.A.); giulia.massaro@unibo.it (G.M.); claudio.capobianco@studio.unibo.it (C.C.); giuseppe.pio.piemontese@gmail.com (G.P.P.); alberto.spadotto@studio.unibo.it (A.S.); sebastiano.toniolo@studio.unibo.it (S.T.); angelo.caponetti@studio.unibo.it (A.G.C.); raffaello.ditaranto@studio.unibo.it (R.D.); vanda.parisi@studio.unibo.it (V.P.); matteo.minnucci@studio.unibo.it (M.M.); valentina.ferrara7@studio.unibo.it (V.F.); nazzareno.galie@unibo.it (N.G.); elena.biagini@aosp.bo.it (E.B.)

* Correspondence: berardinialessandra@gmail.com

Abstract: Severe mitral valve regurgitation (MR) carries a significant burden both in prognosis and quality of life of patients, as well as on healthcare systems, with high rates of hospitalization for heart failure. While mitral valve surgery constitutes the first-line treatment option for primary MR in suitable patients, surgical treatment for secondary severe MR remains controversial, with a substantial lack of evidence on a survival benefit. In recent decades, percutaneous mitral valve repair has emerged as an alternative treatment for patients deemed not suitable for surgery. Among several devices under development or evaluation, the MitraClip system is the most widespread and is supported by the strongest evidence. While the role of MitraClip in patients with chronic primary MR who are not deemed suitable for surgery is well established, with consistent data showing improvement in both prognosis and quality of life, MitraClip treatment in secondary MR is a rapidly evolving field. Two recent randomized clinical trials generated apparently controversial results but actually provided an interesting pathophysiologic frame that could help discerning patients who will benefit from the procedure versus patients who will not. In this review, we will discuss current treatment options for mitral regurgitation, focusing on percutaneous mitral valve repair with the MitraClip system.

Keywords: mitral regurgitation; transcatheter mitral valve repair; TMVR; MitraClip; heart failure

\section{Mitral Valve Anatomy and Mitral Valve Regurgitation}

The mitral valve apparatus comprises four main components: mitral valve leaflets (anterior and posterior), mitral annulus, chordae tendineae and papillary muscles. Normal mitral valve function allows unidirectional blood flow from the left atrium (LA) to the left ventricle (LV) during diastole, avoiding blood regurgitation in the opposite direction during systole. Mitral valve closing relies on a complex balance between the tethering forces of chordae tendineae and mitral annulus and the closing force generated by LV contraction that results in appropriate coaptation and symmetrical apposition of the leaflets. Any anatomical and/or functional abnormality of one or more of these structures can lead to mitral regurgitation [1].

Primary (degenerative) mitral regurgitation is related to anatomical abnormality of valve leaflets and/or chordae tendinae, while secondary (functional) mitral regurgitation occurs in the setting of LV dilation and systolic dysfunction, which compromises the tethering 
forces through annular dilation and retraction or displacement of papillary muscle/chordae tendinae, as well as the closing forces due to systolic dysfunction/dyssynchrony [1-5].

Different lesions can determine mitral regurgitation through different mechanisms (Table 1).

Table 1. Functional Carpentier classification [6] of mitral regurgitation and commonest underlying etiologies.

\begin{tabular}{ccc}
\hline Leaflet Motion & Lesion & Etiology \\
\hline Type I: normal leaflet motion & $\begin{array}{c}\text { Annular dilation/distortion } \\
\text { Leaflet perforation }\end{array}$ & $\begin{array}{c}\text { Dilated cardiomyopathy, left } \\
\text { atrial dilation, Endocarditis }\end{array}$ \\
\hline $\begin{array}{c}\text { Type II: excess leaflet motion } \\
\text { (prolapse/flail) }\end{array}$ & $\begin{array}{c}\text { Chordal elongation/rupture } \\
\text { Papillary muscle rupture }\end{array}$ & $\begin{array}{c}\text { Degenerative valve disease } \\
\text { Ischemic cardiomyopathy, } \\
\text { trauma, endocarditis }\end{array}$ \\
\hline $\begin{array}{c}\text { Type IIIA: restricted } \\
\text { systo-diastolic leaflet motion }\end{array}$ & $\begin{array}{c}\text { Leaflet and/or chordae } \\
\text { thickening/retraction, leaflet } \\
\text { calcification/fusion, } \\
\text { commissural fusion }\end{array}$ & $\begin{array}{c}\text { Rheumatic heart disease, } \\
\text { carcinoid heart disease, } \\
\text { dilated cardiomyopathy, } \\
\text { radiation }\end{array}$ \\
\hline $\begin{array}{c}\text { Type IIIB: restricted systolic } \\
\text { leaflet motion }\end{array}$ & $\begin{array}{c}\text { Papillary muscle } \\
\text { displacement } \\
\text { or chordal tethering }\end{array}$ & $\begin{array}{c}\text { Ischemic or dilated } \\
\text { cardiomyopathy }\end{array}$ \\
\hline
\end{tabular}

\section{Pathophysiology and Natural History}

Structural, functional and hemodynamic consequences of mitral regurgitation are related to the timing in which valve disease develops.

In acute MR there is acute LV and LA volume overload. Since the mitral valve is functionally in parallel with the aortic valve, mitral regurgitation translates to a sudden decrease in LV afterload and forward cardiac output. Sudden volume overload into a non-dilated LA results in an increase in pulmonary venous pressure and then in pulmonary edema.

In chronic MR, there is an initial compensated stage in which eccentric remodeling of $\mathrm{LV}$ can preserve an appropriate forward cardiac output by the increase in LV diastolic volume and stroke volume. However, with progressive LV dilation, LV systolic dysfunction eventually occurs, and there is a progressive hemodynamic compromise with reduction of forward cardiac output and progressive increase in pulmonary venous pressure [7-10].

If not treated, severe MR is associated with poor prognosis irrespective of its etiology, and heart failure (HF) symptoms development, new-onset atrial fibrillation, LV systolic dysfunction and increase in systolic pulmonary artery pressure (sPAP) constitute the main factors associated with worse outcomes [11-15].

\section{Mitral Regurgitation Assessment and Grading}

Echocardiography is the primary diagnostic exam in the screening, assessment and grading of mitral regurgitation. It allows a careful assessment of all the structures of mitral valve apparatus, as well as LV volumes and function, LA dimensions and hemodynamic parameters such as sPAP and LV filling pressure estimation. Transesophageal echocardiography (TEE) is widespread used to further characterize the mechanism of MR and in the evaluation for surgical repair/percutaneous repair feasibility.

MR grading is based on qualitative, semi-quantitative and quantitative parameters that can be evaluated through different echo modalities (color, continuous wave doppler, pulsed doppler). When feasible, the PISA (proximal isovelocity surface area) method, used to estimate the size of the effective regurgitant orifice area (EROA), is the most recommended tool in MR severity assessment. According to current European Society of Cardiology (ESC) guidelines, an EROA $>40 \mathrm{~mm}^{2}$ and a regurgitant volume (RVol) $>60 \mathrm{~mL}$ indicate severe primary mitral regurgitation, while in secondary MR, lower cutoffs are used (EROA $>20 \mathrm{~mm}^{2} ; \mathrm{RVol}>30 \mathrm{~mL}$ ) due to evidence supporting a negative prognostic impact of secondary MR above those values [16-19]. The PISA method is based on the 
assumption of hemispheric symmetry of the velocity distribution proximal to the circular regurgitant lesion, which may not hold for eccentric jets, multiple jets, or complex or elliptical regurgitant orifices. Practically, the geometry of the PISA varies depending on the shape of the orifice and mitral valve leaflets surrounding the orifice. In functional MR, the PISA might look like an ellipsoidal shape, and two separate MR jets originating from the medial and lateral sides of the coaptation line can be observed on 2D echo. When the shape of the flow convergence zone is not a hemisphere, the PISA method may underestimate the degree of functional MR, and in every case the PISA method could not be applied, assessment of all the other parameters is needed. A list of the main echocardiographic parameters is shown in Table 2 [3,12-15].

Table 2. Main echocardiographic findings suggesting severe MR.

\begin{tabular}{|c|c|}
\hline Echocardiographic Parameters & Data/Values Suggestive of Severe MR \\
\hline \multicolumn{2}{|l|}{ Qualitative } \\
\hline - Morphologic assessment & Prolapse/flail, chordae or papillary muscle rupture \\
\hline - Color flow MR Jet & $\begin{array}{l}\text { Large central jet or eccentric jet reaching the } \\
\text { posterior wall of LA }\end{array}$ \\
\hline - Flow convergence zone & Large flow convergence \\
\hline - CW signal of MR jet & Dense/triangular \\
\hline \multicolumn{2}{|l|}{ Semi-quantitative } \\
\hline - Vena contracta width & $\geq 7 \mathrm{~mm}$ \\
\hline - Pulmonary vein flow & Systolic flow reversal \\
\hline \multicolumn{2}{|l|}{ Quantitative } \\
\hline - EROA & $\geq 40 \mathrm{~mm}^{2}\left(\geq 20 \mathrm{~mm}^{2}\right.$ in secondary MR) \\
\hline - Regurgitant volume & $\geq 60 \mathrm{ml}(\geq 30 \mathrm{ml}$ in secondary MR) \\
\hline - Regurgitant fraction & $\geq 50 \%$ \\
\hline \multicolumn{2}{|l|}{ Additional evaluation } \\
\hline - $\quad$ LV and LA size & $\begin{array}{l}\text { Chamber dilation (may not be present in acute MR; } \\
\text { in secondary MR may be a consequence of } \\
\text { underlying LV dysfunction) }\end{array}$ \\
\hline - Estimated sPAP & $>50 \mathrm{mmHg}$ \\
\hline
\end{tabular}

\section{Surgical Treatment of Mitral Regurgitation}

In chronic primary MR, medical therapy of hypertension and/or HFrEF is recommended, if indicated. However, valve surgery (repairing when feasible or replacement) [20-22] is the preferred treatment for chronic primary MR. Surgery is indicated in symptomatic patients with severe MR and left ventricle ejection fraction (LVEF) $>30 \%$ (Class of recommendation, COR I; Level of evidence, LOE B). In symptomatic patients with severe LV dysfunction (LVEF $<30 \%$, LVESD $>55 \mathrm{~mm}$ ) refractory to medical therapy, surgery could be considered if the surgical risk is low and there are no major comorbidities (mitral valve repair: COR IIa, LOE C; mitral valve replacement: COR IIb, LOE C) [3]. Surgical treatment in asymptomatic patients is indicated if there are signs of LV dilation and dysfunction (LV EF $<60 \%$ or LVESD $>45 \mathrm{~mm}$ ) (COR I, LOE B) or in patients with preserved LV function (LVEF $>60 \%$, LVESD $<45 \mathrm{~mm}$ ) presenting new-onset atrial fibrillation (AF) or sPAP $>50 \mathrm{mmHg}(\mathrm{COR}$ IIa, LOE B) or in patients with preserved LV function (LVEF > 60\%, LVESD 40-44 mm) presenting flail leaflet or significant LA dilation (LAVI $>60 \mathrm{~mL} / \mathrm{m}^{2}$ in sinus rhythm) when there is high likelihood or durable valve repair (COR IIa, LOE C) [3,23,24].

In chronic secondary MR, medical and device (CRT if indicated) treatment of HFrEF is recommended [25-27], as well as treatment of underlying coronary artery disease, if present. Mitral valve surgery (either repair or replacement) failed to demonstrate a survival 
benefit in this setting [28-30] and only improves symptoms, so current guidelines suggest surgical treatment of secondary MR in patients with $\mathrm{LVEF}>30 \%$ undergoing coronary artery bypass surgery (CABG) (COR I, LOE C) or symptomatic patients with LVEF $<30 \%$ with evidence of myocardial viability and an option for revascularization (COR IIa, LOE C). Mitral valve surgery in symptomatic patients without options for revascularization could be evaluated in patients with LVEF > 30\% and low surgical risk (COR IIb, LOE C) [3]. As already mentioned before, mitral valve surgery in secondary MR lacks robust evidence derived from randomized clinical trial, since current guidelines' indications refer to single-center retrospective studies. The newer interest in the field generated by the development of percutaneous mitral valve repair (PMVR) contributed to filling this gap in knowledge. The ongoing MATTERHORN trial will be the first randomized clinical trial directly comparing MV surgery VS MitraClip in the setting of severe secondary MR in surgical high-risk patients. Acute mitral regurgitation treatment is not the subject of this review and will not be discussed. Table 3 resumes current guidelines' indications for MR treatment.

Table 3. Current indications for MR treatment.

\begin{tabular}{|c|c|c|}
\hline Clinical Setting & Indication for Intervention & Intervention \\
\hline \multirow{3}{*}{$\begin{array}{l}\text { Symptomatic chronic primary } \\
\text { mitral regurgitation }\end{array}$} & - $\quad \mathrm{LVEF}>30 \%$ & Surgery (COR I, LOE B) \\
\hline & $\begin{array}{l}\text { - LVEF }<30 \% \text {, LVESD }>55 \text { mmlow surgical risk, } \\
\text { no major comorbidities }\end{array}$ & $\begin{array}{l}\text { Repair (COR IIa, LOE C) or } \\
\text { Replacement (COR IIb, LOE C) }\end{array}$ \\
\hline & $\begin{array}{l}\text { - LVEF }<30 \% \text {, LVESD }>55 \text { mmhigh surgical risk } \\
\text { and/or major contraindication for surgery }\end{array}$ & $\begin{array}{l}\text { Edge to edge TMVR if feasible (COR } \\
\text { IIb, LOE C) }\end{array}$ \\
\hline \multirow{3}{*}{$\begin{array}{l}\text { Asymptomatic chronic primary } \\
\text { mitral regurgitation }\end{array}$} & - $\mathrm{LVEF}<60 \%$ and/or LVESD $>45 \mathrm{~mm}$ & Surgery (COR I, LOE B) \\
\hline & $\begin{array}{l}\text { - } \quad \text { LVEF }>60 \% \text { and new onset } \mathrm{AF} \text { or } \\
\text { sPAP }>50 \mathrm{mmHg}\end{array}$ & Surgery (COR IIa, LOE B) \\
\hline & $\begin{array}{l}\text { - LVEF }>60 \%+\text { LVESD } 40-44 \mathrm{~mm} \text { and flail } \\
\text { leaflet or severe LA dilation; low surgical risk }\end{array}$ & $\begin{array}{l}\text { Repair if high likelihood of durable } \\
\text { repair (COR IIa, LOE C) }\end{array}$ \\
\hline \multirow{4}{*}{$\begin{array}{l}\text { Symptomatic chronic secondary } \\
\text { mitral regurgitation }\end{array}$} & - $\quad$ LVEF $>30 \%$ undergoing CABG & Surgery (COR I, LOE B) \\
\hline & - $\quad$ LVEF $>30 \%$, low surgical risk & Surgery (COR Ilb, LOE C) \\
\hline & $\begin{array}{l}\text { - LVEF }<30 \% \text { with myocardial viability and } \\
\text { option for revascularization }\end{array}$ & Surgery (COR IIa, LOE C) \\
\hline & - $\mathrm{LVEF}<30 \%$, high surgical risk & $\begin{array}{l}\text { Edge to edge TMVR if feasible (COR } \\
\text { IIb, LOE C); ventricular assist device } \\
\text { or transplantation program (COR IIb, } \\
\text { LOE C) }\end{array}$ \\
\hline
\end{tabular}

\section{Percutaneous Treatment of Mitral Regurgitation}

Percutaneous mitral valve repair consists of less invasive procedures targeting selected patients with symptomatic chronic primary or secondary MR. Among several devices and techniques that are in ongoing development/evaluation, the MitraClip system (Abbott Laboratories, Menlo Park, CA, USA) is the most widespread and the one with the most robust evidence.

MitraClip is a percutaneous mitral valve repair system that imitates the surgical Alfieri technique, which connects the middle segments of the mitral leaflets through surgical stitches in order to create a double valve orifice and reduce mitral regurgitation [31].

The MitraClip procedure is performed in the catheterization laboratory using echocardiographic and fluoroscopic guidance (Figure 1). The patient is under general anesthesia and systemic anticoagulation with an activated clotting time (ACT) target $>250 \mathrm{~s}$ administered. The MitraClip itself is a cobalt chromium clip covered with a polypropylene fabric whose function is to grasp and approximate two opposite segments of the anterior and posterior leaflet. The clip is delivered percutaneously through a venous femoral access. 
Transseptal puncture is performed in order to introduce the clip delivery system into the left atrium and then into the left ventricle. Once in the left ventricle, the delivery system is steered and aligned over the origin of the regurgitant jet, and leaflet grasping is performed. In its most recent version, the MitraClip system allows for independent leaflets grasping. Once adequate grasping is obtained, desired position of the clip is confirmed and functional assessment of the mitral valve is done, the clip can be released from the delivery system or reopened and repositioned. Residual MR can be targeted by positioning additional clips [32]. Procedural success is defined as proper placement of the device without procedural mortality and with reduction in post-procedural MR by $\geq 1$ grade from baseline and to an absolute level of $\leq$ moderate MR.

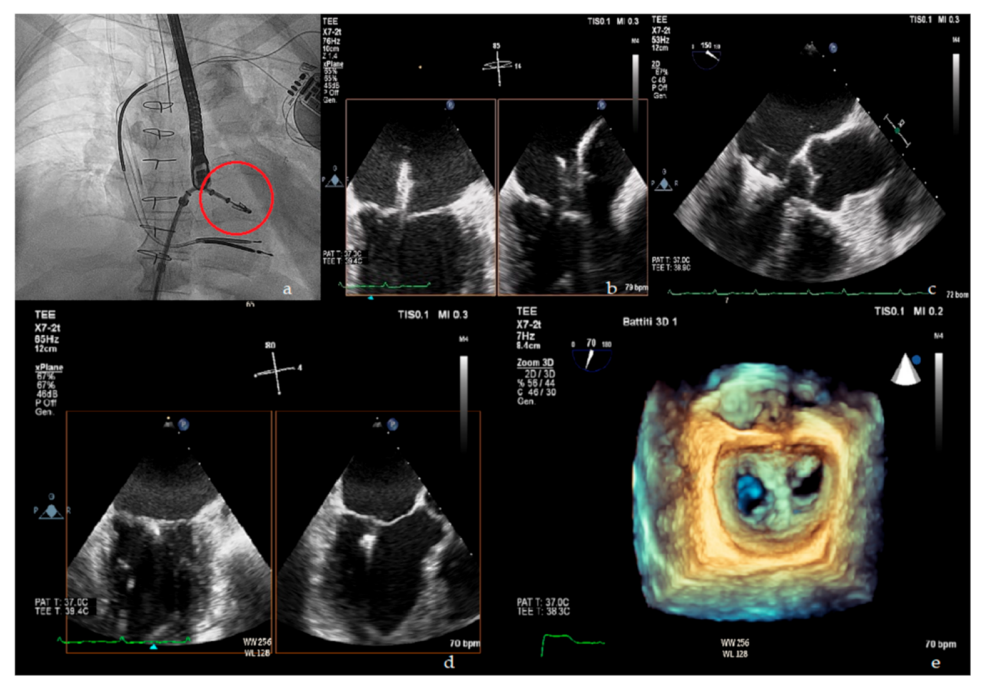

Figure 1. Upper panel: (a) fluoroscopic view of MitraClip delivery system (red circle); (b) X plane transoesophageal echocardiogram (TOE) view of MitraClip in left atrium; (c) TOE left ventricle outflow tract (LVOT) view of MitraClip positioning. Lower panel: (d) X plane TOE view of final clip release; (e) 3D en face view showing the double orifice shape of the mitral valve after clip implantation.

MitraClip suitability and contraindications: Eligibility for MitraClip procedure relies on the analysis of specific anatomical criteria that includes evaluation of leaflets morphology and calcification, planimetric MV area, coaptation length and depth and flail gap and width (Figure 2). Table 4 resumes the optimal suitability criteria as defined in the EVEREST trial [33], as well as suboptimal valve morphology criteria in which MitraClip procedure can still be performed, however with lower success rates [34,35].

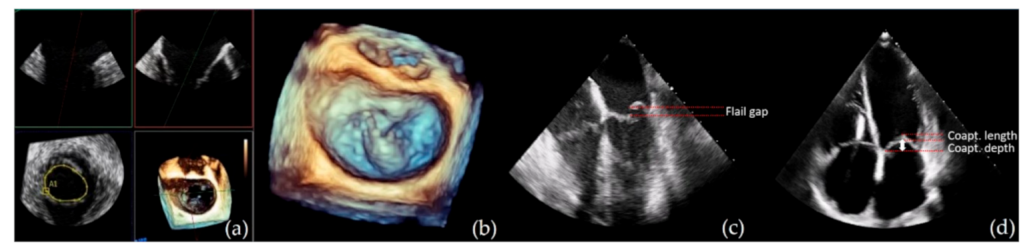

Figure 2. Showing some examples of echocardiographic imaging modalities commonly used for MitraClip suitability evaluation. From left to right: (a) 3D Xplane mitral valve area (MVA) measurement; (b) 3D en face view showing a P2 flail and chordal rupture; (c) Transesophageal echocardiography (TEE) four chamber view for flail gap evaluation; (d) transthoracic echocardiogram (TTE) four chamber view screening of coaptation depth and length in secondary MR. 
Table 4. Suitability criteria for MitraClip procedure.

\begin{tabular}{ccc}
\hline Parameters & Optimal Suitability & Suboptimal/Conditional Suitability \\
\hline Pathology location & A2-P2 & A1-P1 or A3-P3 \\
Calcification & Absent & $\begin{array}{c}\text { Mild calcification, not in grasping zone, } \\
\text { annular calcification }\end{array}$ \\
Leaflet mobility & Normal & Systolic restriction \\
Mitral valve area & $\geq 4 \mathrm{~cm}^{2}$ & $\geq 3 \mathrm{~cm}^{2}$ \\
Coaptation depth $^{\dagger}$ & $<11 \mathrm{~mm}$ & $\geq 11 \mathrm{~mm}$ \\
Coaptation length $^{\dagger}$ & $\geq 2 \mathrm{~mm}$ & $<2 \mathrm{~mm}$ \\
Mobile length of PML & $\geq 10 \mathrm{~mm}$ & $7-10 \mathrm{~mm}$ \\
Flail width & $\leq 15 \mathrm{~mm}$ & $>15$ mm with large annulus size and with \\
Flail gap & $<10 \mathrm{~mm}$ & the possibility of multiple clip positioning \\
\hline
\end{tabular}

${ }^{\dagger}$ specific criteria for secondary MR evaluation.

Procedure contraindications are unfavorable anatomy, intolerance to procedural anticoagulation or post-procedural antiplatelet therapy, active endocarditis, rheumatic MV disease, mitral stenosis, femoral venous, superior vena cava (SVC) or inferior vena cava (IVC) thrombosis or intracardiac left-sided thrombosis or masses, life expectancy $<1$ year.

Complications: the main procedural and peri-procedural complications are pericardial effusion/tamponade, thrombus formation, access site bleeding, clip detachment from a single leaflet or device embolization, development of mitral stenosis, acute kidney injury and neurological events [36-38]. In the EVEREST II trial, major adverse events rate at 30 days was $15 \%$ [36]. In a subsequent meta-analysis also including EVEREST II, the weighted mean rate of major adverse effect at 30 days was 17\% [37]. ACCESS-EU, a real-world post-approval study including a high risk, elderly population, mainly affected by secondary MR, demonstrated a 30 days major adverse events rate of $17 \%$ [39]. More recent trials on secondary MR, which will be later discussed in this review, demonstrated procedural complication rates of $8.5 \%$ and $14.6 \%$ [40,41].

\section{MitraClip in the Current Practice for Primary MR}

The 2017 ESC guidelines suggest evaluation for percutaneous mitral valve repair in symptomatic patients with severe primary MR who are judged inoperable or at high surgical risk (COR IIb, LOE C) [3]. This indication mainly derives from data of the EVEREST II trial.

In the EVEREST II trial, 279 patients with moderate-to-severe MR (according to ACC/AHA criteria) were randomized in a 2:1 ratio to undergo either MitraClip procedure or mitral valve surgery. At 12 months follow up, while there was no statistical significance in mortality between the two groups ( $6 \%$ in both groups), and residual $\geq 3 \mathrm{MR}$ ( $21 \%$ vs. $20 \%$ ) repeat surgery was more frequent in MitraClip group ( $20 \%$ vs. $2 \%$ ), driving the primary composite endpoint of freedom from death, repeat surgery and residual $\geq 3 \mathrm{MR}$ in favor of surgery [36]. A survival benefit comparable to surgery has also been confirmed at 5 years follow up [42]. MitraClip demonstrated a durable benefit on quality of life and functional status as well as HF hospitalization reduction at 1 year in REALISM study that enrolled patients at prohibitive risk for surgery [43].

\section{MitraClip for Secondary MR Treatment}

The 2017 ESC guidelines suggest evaluation for percutaneous mitral valve repair in symptomatic patients with severe LV dysfunction, without indication for coronary revascularization and at high risk for surgery (COR IIb, LOE C) [3]. These recommendations derived from the lack of evidence on survival benefit of the MitraClip procedure, whose indication is intended only for symptom relief. However, these guidelines do not incorporate the results of two recent trials, namely the COAPT and the MITRA -FR that raised new interest and potential new indications for MitraClip procedure in secondary MR in HFrEF patients. 
7.1. COAPT Trial (Cardiovascular Outcomes Assessment of the MitraClip Percutaneous Therapy for Heart Failure Patients with Functional Mitral Regurgitation)

COAPT was a multicenter, randomized, controlled, parallel-group, open-label trial of transcatheter mitral-valve repair with the MitraClip device in patients with heart failure (LVEF 20-50\%) who remained symptomatic (NYHA II-IV) despite the use of stable maximal doses of guideline-directed medical therapy (GDMT) and cardiac resynchronization therapy (if appropriate) and moderate-to-severe or severe (3-4+) mitral regurgitation according to the ACC/AHA guidelines. The study enrolled 614 patients who were anatomically eligible for MitraClip and were considered not eligible for mitral valve surgery. Key exclusion criteria were LVESD > $70 \mathrm{~mm}$ and severe pulmonary hypertension (sPAP > $70 \mathrm{mmHg}$ ). The enrolled patients were randomized on a 1:1 ratio to the device group (MitraClip plus GDMT) and control group (GDMT alone). In the device group, there was consistent mitral regurgitation reduction with a $98 \%$ procedural success and a $94.8 \%$ rate of $M R<2+$ at 12 months. The primary endpoint, defined as all hospitalizations for heart failure within 24 months of follow-up, significantly improved in the device group compared with the control group ( 35.8 vs. $67.9 \%$ ). Among the secondary endpoints, the device group performed better compared to the control group in 2-year all-cause mortality (29.1 vs. 46.1\%), NYHA functional class and Kansas City Cardiomyopathy Questionnaire (KCCQ) score. Primary safety endpoint, defined as freedom from device-related complication at 12 months, was met in $94.8 \%$ of the patients compared to the prespecified target of $88 \%$.

\subsection{MITRA-FR}

MITRA-FR (Percutaneous Repair with the MitraClip Device for Severe Functional/ Secondary Mitral Regurgitation) was a multicenter, randomized, open-label, controlled phase 3 trial that enrolled 304 patients with symptomatic (NYHA II-IV) HFrEF (LVEF $15-40 \%$ ) despite the use of medical therapy and moderate to severe or severe (3-4+) MR according to the ESC criteria. As in the COAPT trial, all patients were anatomically eligible for MitraClip and were considered not to be candidates for mitral valve surgery. The patients were randomized on a 1:1 ratio to receive medical therapy alone (control arm, $n=152$ ) or MitraClip plus medical therapy (treatment arm, $n=152$ ). A consistent mitral regurgitation reduction (MR grade $<3$ ) was achieved in $91.9 \%$ of the treatment arm at discharge and in $82 \%$ at 12 months follow up. Periprocedural complications occurred in $14.6 \%$ of the treatment arm, including procedural failure in $4.2 \%$. There was no statistical significance in the composite primary endpoint, defined as death from any cause or unplanned hospitalization for heart failure at 12 months, between the treatment arm and the control arm (54.6 vs. $51.3 \%$ ). The two arms showed similar results in 12 months mortality ( 24.3 vs. $22.4 \%$ ), unplanned HF hospitalization (48.7 vs. $47.4 \%$ ) cardiovascular death (21.7 vs. $20.4 \%$ ) and NYHA functional class improvement. There was no difference in the safety endpoint of serious adverse events at 12 months between the treatment and the control arm (82.2 vs. $79.6 \%)$; however, there was a significant increase in ischemic or hemorrhagic stroke, renal-replacement therapy and severe hemorrhage in the treatment arm.

\section{Similarities and Differences between COAPT and MITRA-FR}

Although the two trials had a similar design and target population, i.e., symptomatic patients with HFrEF despite medical therapy and moderate to severe mitral regurgitation, they showed substantially opposite results: the COAPT study demonstrated a significant benefit in the device group on HF hospitalization and all-cause mortality at 24 months, as well as in the QOL assessment (NYHA functional class and KCCQ score), while MITRA-FR failed to show any difference either on 12 months mortality and HF hospitalization or on NYHA functional class improvement $[40,41,44]$.

A possible explanation for this discrepancy could be found in the analysis of the three major differences between these two trials. 


\subsection{Medical and Device Therapy at the Baseline}

In the COAPT trial, baseline therapy was defined as "stable maximal doses of guidelinedirected medical therapy and cardiac resynchronization therapy (if appropriate)". This translated into an optimization of the therapy prior to randomization and few major adjustments in treatment during follow-up. In the MITRA-FR trial, medical therapy was not optimized in all patients at baseline, and multiple adjustments in medical treatment occurred during follow-up, in both the treatment and control arms, resulting in a "real world practice"-like setting. We could argue that this difference could have reduced the impact of the MitraClip procedure on the trial outcomes, e.g., there was no statistical difference between the two study arms in NYHA functional class improvement, but there was a statistically significant improvement in NYHA class from baseline to follow up in both groups. In addition, medical and device therapy optimization could have led to a reduction of MR severity in some patients, resulting in a lack of benefit/lack of indication of MitraClip procedure.

\subsection{Echocardiographic Parameters at Baseline}

Although both trials enrolled patients with comparable clinical and demographic characteristics, there are some differences in the echocardiographic inclusion criteria and baseline parameters. First of all, COAPT trial excluded patients with LVESD $>70 \mathrm{~mm}$, thus excluding patients with very severe LV dilation and dysfunction. Mean indexed LVEDV in COAPT trial patients was $\simeq 31 \mathrm{~mL} / \mathrm{m}^{2}$ lower than MITRA-FR with comparable mean LVEF. Mitral severity grading was made using different parameters due to different European and American guidelines for MITRA-FR and COAPT, respectively. Due to this discrepancy, COAPT patients demonstrated significantly higher mean values of EROA and Rvol in comparison to MITRA-FR patients. More than this, in COAPT, when PISA was not feasible or EROA value was inferior to the cutoff, additional echocardiographic parameters were needed and pre-specified to confirm eligibility. A comparison of the echocardiographic baseline parameters is shown in Table 5. Interestingly, the subgroup analysis of COAPT trial including the patient with lesser degree of MR severity and a higher degree of LV dilation failed to demonstrate statistical significance between device and control. This observation suggests that MR relative severity, rather than absolute severity, could be of critical importance in patients' selection.

Table 5. Main echocardiographic differences between the two study populations.

\begin{tabular}{ccc}
\hline Baseline Parameters & COAPT & MITRA-FR \\
\hline Etiology of LV dysfunction & $60.7 \%$ & $59.6 \%$ \\
Ischemic & $39.3 \%$ & $40.4 \%$ \\
Non-ischemic & $101 \pm 34 \mathrm{~mL} / \mathrm{m}^{2}$ & $135 \pm 35 \mathrm{~mL} / \mathrm{m}^{2}$ \\
LVEDV & $>20 \%,<50 \%$ & $>15 \%,<40 \%$ \\
LVEF inclusion criteria & $31 \% \pm 9 \%$ & $33 \pm 7 \%$ \\
Mean LVEF & $>30 \mathrm{~mm}^{2}$ & $>20 \mathrm{~mm}^{2}$ \\
EROA cutoff & $41 \pm 15 \mathrm{~mm}^{2}$ & $31 \pm 10 \mathrm{~mm}^{2}$ \\
Mean EROA & $86 \%$ & $48 \%$ \\
EROA $>30 \mathrm{~mm}^{2}$ & LVESD $<70 \mathrm{~mm}$ & \\
& SPAP $<70 \mathrm{mmHg}$ & \\
Additional criteria & RV dysfunction $<$ moderate & \\
\end{tabular}

\subsection{Procedural Outcomes}

As shown in Table 6, although post-procedural MR reduction was substantially comparable between the two studies, 1 year echocardiographic follow up demonstrated that in COAPT there was a higher rate of durable MR reduction. It is unknown if this is a consequence of differences of baseline echocardiographic parameters (greater LV dilation 
in MITRA-FR patients) or if it can at least partially be attributed to different procedure approaches, such as a higher percentage of COAPT patient treated with more than one clip.

Table 6. Main procedural outcomes.

\begin{tabular}{ccc}
\hline Outcome & COAPT & MITRA-FR \\
\hline Post-procedural residual MR $\leq 2$ & $95 \%$ & $91 \%$ \\
1 year follow up residual $\geq 3 \mathrm{MR}$ & $5 \%$ & $17 \%$ \\
$\%$ of patients treated with $>1$ clip & $64 \%$ & $54 \%$ \\
\hline
\end{tabular}

\section{A New Concept in the Evaluation of MR Severity: Proportionate vs. Disproportionate MR}

The opposite results of MITRA-FR and COAPT renewed the need for a better understanding of pathophysiological relationship between LV dysfunction and secondary MR and a more accurate prognostic stratification of these patients that extends towards the current model of evaluation of LV dysfunction and secondary MR as almost separate entities.

A new conceptual framework for comprehensive evaluation of secondary MR was proposed by Grayburn and colleagues [45].

In the proposed model, severe secondary MR is not defined with a fixed cut-off of EROA and regurgitant volume, but these parameters must be indexed to the degree of $\mathrm{LV}$ dilation and systolic dysfunction. As a consequence, in order to produce a severe MR, defined as a regurgitant fraction $>50 \%$, expected EROA and Regurgitant volume are different on each patient [46]. Using a different cutoff of EROA could further classify the patients into three groups:

- Patients whose MR severity is proportionate to the degree of LV dilation and dysfunction (proportionate MR).

- Patients whose MR severity is unexpectedly more compared to their LV dilation and dysfunction (disproportionate MR).

- Patients whose MR, despite an EROA $>20 \mathrm{~mm}^{2}$, is unlikely to be severe given the greater degree of $\mathrm{LV}$ dilation (moderate MR).

This framework could potentially reconcile the controversial results of COAPT and MITRA-FR trial: while most COAPT patients could be classified as disproportionate MR and thus demonstrate a substantial benefit on treatment of MR, MITRA-FR patients are mainly classified as proportionate MR, in which MR has a relatively lower burden on the outcome that is mainly driven by LV dilation and dysfunction. Given the results of COAPT and MITRA-FR trials, we can assume that in selected patients with severe secondary MR carefully evaluated in relation to the underlying LV dysfunction, the MitraClip procedure could be of potential benefit on both symptoms and survival.

\section{Controversies of the "Disproportionate MR" Framework}

More recent subgroup post-hoc analysis on MITRA-FR and COAPT tried to validate the disproportionate MR framework, showing conflicting results: in a COAPT subgroup analysis, the patients with the most severe LV dysfunction and relatively less severe MR (MITRA-FR-like patients) did not show a significant benefit from the MitraClip procedure, thus supporting the disproportionate MR framework [47]. In opposition, MITRA-FR subgroup analysis failed to identify a subgroup of patients based on LV dysfunction, MR severity or a combination of those parameters (including those deemed as having disproportionate MR) who could benefit from percutaneous correction from transcatheter correction using the MitraClip system, thus not supporting the disproportionate MR framework [48]. Another not prespecified post-hoc analysis of COAPT failed to demonstrate the role of EROA and LVEDV as predictors of clinical response after MitraClip procedure, although there was a trend towards higher values of EROA and smaller values of LVEDV among the patients with the best clinical outcome [49]. 
All these results are limited from the small sample size, the post-hoc setting of the analyses, and the same limitations and differences of the main trials already mentioned before (medical therapy and exclusions criteria, in particular exclusion of patients with severe $\mathrm{RV}$ dysfunction, severe pulmonary hypertension and/or severe tricuspid regurgitation in COAPT but not in MITRA-FR). Taken together, we can conclude that the disproportionate MR framework is an interesting theoretic model that is, however, not readily applicable in clinical practice to make therapeutic choices in the individual patient [50]. Together with anatomic, echocardiographic and clinical selection criteria applied in the different trials, a special emphasis should be dedicated to the optimization of medical treatment before eventual percutaneous mitral valve repair.

\section{Conclusions}

Percutaneous mitral valve repair with the MitraClip system constitutes a safe, feasible and effective treatment for primary MR in patients who are not suitable for surgery. In secondary MR, recent evidence of a survival benefit in selected HFrEF patients treated with MitraClip could lead to new indications for percutaneous mitral valve repair in this population, as well as to a paradigm shift in the evaluation of secondary MR. HF therapy optimization and accurate patient selection, focusing on those with severe mitral regurgitation but without underlying severely advanced LV and/or severe RV dysfunction or severe tricuspid regurgitation, could allow these recent trials' results to be replicated in real-world clinical practice. Patients with admissions for heart failure or severely symptomatic ambulatory patients should be systematically assessed for MR. These assessments should be performed after a sufficiently prolonged observation period under optimal medical therapy, including modern renin-angiotensin-aldosterone system inhibitors at the maximum tolerated dose and cardiac resynchronization therapy if indicated. Futility should also be avoided, in terms of old age or high expected mortality due to comorbidities or excessively depressed LV function to allow sufficient recovery. In this context, percutaneous mitral valve repair can represent a life-saving treatment and not only a palliative strategy.

\section{Open Questions}

- Whether proportionate and disproportionate secondary MR represent different stages of the same disease or different clinical entities is unclear.

- A better understanding of pathophysiology of secondary MR could help identify early markers for disproportionate MR and thus prompt treatment.

- Potential diagnostic performance improvement with cardiac MRI needs to be evaluated. Cardiac MRI could overcome the already mentioned limitations and potential underestimation of the PISA method in MR severity assessment, but current guidelines on valvular disease, as well as the trials on MR treatment presented in this review, does not include it in the diagnostic/therapeutic workup; thus it is still not known if a performance improvement in severity assessment could translate into better patients selection and/or better outcomes; moreover, recent studies have shown possible prognostic implications of left ventricular scar extension detected with cardiac magnetic resonance imaging in patients with secondary mitral regurgitation [51].

- Beyond MitraClip: In addition to the MitraClip system, several PMVR systems are currently under investigation. One of these is the Edwards PASCAL system, an edge-to-edge mitral valve repair system that has been shown promising results both in safety and efficacy in the 30 days data of the CLASP study [52], as well as a potential to extend MR treatment to patients who do not fulfill eligibility criteria for MitraClip. Moreover, a further therapeutic approach in the treatment of severe mitral regurgitation is represented by a transcatheter mitral valve replacement (TMVR) treatment; this procedure has emerged as a potential therapy for inoperable or highsurgical risk patients with symptomatic mitral regurgitation. The early feasibility of TMVR has been demonstrated in several prior studies [53], with the Tendyne system (Abbott Structural, Santa Clara, CA, USA) representing the largest experience. 
Author Contributions: Conceptualization, S.S. and A.B.; writing-original draft preparation, S.S., C.C., G.S., A.A., G.M., A.S. and G.P.P.; writing-review and editing, S.S., A.B., E.B., A.G.C. and R.D.; visualization, M.M., V.F., V.P. and S.T.; supervision, E.B., A.B. and N.G. All authors have read and agreed to the published version of the manuscript.

Funding: This research received no external funding.

Conflicts of Interest: The authors declare no conflict of interest.

\section{References}

1. Dal-Bianco, J.P.; Levine, R.A. Anatomy of the mitral valve apparatus: Role of 2D and 3D echocardiography. Cardiol. Clin. 2013, 31, 151-164. [CrossRef] [PubMed]

2. Nkomo, V.T.; Gardin, J.M.; Skelton, T.N.; Gottdiener, J.S.; Scott, C.G.; Enriquez Sarano, M. Burden of valvular heart diseases: A population-based study. Lancet 2006, 368, 1005-1011. [CrossRef]

3. Baumgartner, H.; Falk, V.; Bax, J.J.; De Bonis, M.; Hamm, C.; Holm, P.J.; Iung, B.; Lancellotti, P.; Lansac, E.; Rodriguez Munoz, D.; et al. 2017 ESC/EACTS Guidelines for the management of valvular heart disease. Eur. Heart J. 2017, 38, $2739-2791$. [CrossRef] [PubMed]

4. Sattur, S.; Bates, S.; Movahed, M.R. Prevalence of mitral valve prolapse and associated valvular regurgitations in healthy teenagers undergoing screening echocardiography. Exp. Clin. Cardiol. 2010, 15, e13-e15.

5. Mirabel, M.; Iung, B.; Baron, G.; Messika-Zeitoun, D.; Détaint, D.; Vanoverschelde, J.L.; Butchart, E.G.; Ravaud, P.; Vahanian, A. What are the characteristics of patients with severe, symptomatic, mitral regurgitation who are denied surgery? Eur. Heart J. 2007, 28, 1358-1365. [CrossRef] [PubMed]

6. Carpentier, A. Cardiac valve surgery-The "French correction". J. Thorac. Cardiovasc. Surg. 1983, 86, 323-337. [CrossRef]

7. Debonnaire, P.; Al Amri, I.; Leong, D.P.; Joyce, E.; Katsanos, S.; Kamperidis, V.; Schalij, M.J.; Bax, J.J.; Marsan, N.A.; Delgado, V. Leaflet remodelling in functional mitral valve regurgitation: Characteristics, determinants, and relation to regurgitation severity. Eur. Heart J. Cardiovasc. Imaging 2015, 16, 290-299. [CrossRef]

8. McCutcheon, K.; Manga, P. Left ventricular remodelling in chronic primary mitral regurgitation: Implications for medical therapy. Cardiovasc. J. Afr. 2018, 29, 51-65. [CrossRef]

9. Gaasch, W.H.; Meyer, T.E. Left ventricular response to mitral regurgitation: Implications for management. Circulation 2008, 118, 2298-2303. [CrossRef]

10. Enriquez-Sarano, M.; Avierinos, J.F.; Messika-Zeitoun, D.; Detaint, D.; Capps, M.; Nkomo, V.; Scott, C.; Schaff, H.V.; Tajik, A.J. Quantitative determinants of the outcome of asymptomatic mitral regurgitation. N. Engl. J. Med. 2005, 352, 875-883. [CrossRef]

11. Tribouilloy, C.M.; Enriquez-Sarano, M.; Schaff, H.V.; Orszulak, T.A.; Bailey, K.R.; Tajik, A.J.; Frye, R.L. Impact of preoperative symptoms on survival after surgical correction of organic mitral regurgitation: Rationale for optimizing surgical indications. Circulation 1999, 99, 400-405. [CrossRef] [PubMed]

12. Le Tourneau, T.; Richardson, M.; Juthier, F.; Modine, T.; Fayad, G.; Polge, A.S.; Ennezat, P.V.; Bauters, C.; Vincentelli, A.; Deklunder, G. Echocardiography predictors and prognostic value of pulmonary artery systolic pressure in chronic organic mitral regurgitation. Heart 2010, 96, 1311-1317. [CrossRef] [PubMed]

13. Tribouilloy, C.; Grigioni, F.; Avierinos, J.F.; Barbieri, A.; Rusinaru, D.; Szymanski, C.; Ferlito, M.; Tafanelli, L.; Bursi, F.; Trojette, F.; et al. MIDA Investigators. Survival implication of left ventricular end-systolic diameter in mitral regurgitation due to flail leaflets a long-term follow-up multicenter study. J. Am. Coll. Cardiol. 2009, 54, 1961-1968. [CrossRef] [PubMed]

14. Ma, J.I.; Igata, S.; Strachan, M.; Nishimura, M.; Wong, D.J.; Raisinghani, A.; DeMaria, A.N. Predictive factors for progression of mitral regurgitation in asymptomatic patients with mitral valve prolapse. Am. J. Cardiol. 2019, 123, 1309-1313. [CrossRef]

15. Singh, R.G.; Cappucci, R.; Kramer-Fox, R.; Roman, M.J.; Kligfield, P.; Borer, J.S.; Hochreiter, C.; Isom, O.W.; Devereux, R.B. Severe mitral regurgitation due to mitral valve prolapse: Risk factors for development, progression, and need for mitral valve surgery. Am. J. Cardiol. 2000, 85, 193-198. [CrossRef]

16. Rossi, A.; Dini, F.L.; Faggiano, P.; Cicoira, M.; Frattini, S.; Simioniuc, A.; Gullace, M.; Ghio, S.; Enriquez-Sarano, M.; Temporelli, P.L. Independent prognostic value of functional mitral regurgitation in patients with heart failure. A quantitative analysis of 1256 patients with ischaemic and non-ischaemic dilated cardiomyopathy. Heart 2011, 97, 1675-1680. [CrossRef]

17. Ellis, S.G.; Whitlow, P.L.; Raymond, R.E.; Schneider, J.P. Impact of mitral regurgitation on long-term survival after percutaneous coronary intervention. Am. J. Cardiol. 2002, 89, 315-318. [CrossRef]

18. Grigioni, F.; Enriquez-Sarano, M.; Zehr, K.J.; Bailey, K.R.; Tajik, A.J. Ischemic mitral regurgitation: Long-term outcome and prognostic implications with quantitative Doppler assessment. Circulation 2001, 103, 1759-1764. [CrossRef] [PubMed]

19. Grigioni, F.; Detaint, D.; Avierinos, J.F.; Scott, C.; Tajik, J.; Enriquez-Sarano, M. Contribution of ischemic mitral regurgitation to congestive heart failure after myocardial infarction. J. Am. Coll. Cardiol. 2005, 45, 260-267. [CrossRef] [PubMed]

20. Badhwar, V.; Peterson, E.D.; Jacobs, J.P.; He, X.; Brennan, J.M.; O’Brien, S.M.; Dokholyan, R.S.; George, K.M.; Bolling, S.F.; Shahian, D.M.; et al. Longitudinal outcome of isolated mitral repair in older patients: Results from 14,604 procedures performed from 1991 to 2007. Ann. Thorac. Surg. 2012, 94, 1870-1879. [CrossRef] [PubMed] 
21. Lazam, S.; Vanoverschelde, J.L.; Tribouilloy, C.; Grigioni, F.; Suri, R.M.; Avierinos, J.F.; De Meester, C.; Barbieri, A.; Rusinaru, D.; Russo, A.; et al. Twenty-year outcome after mitral repair versus replacement for severe degenerative mitral regurgitation: Analysis of a large, prospective, multicenter, international registry. Circulation 2017, 135, 410-422. [CrossRef] [PubMed]

22. Suri, R.M.; Vanoverschelde, J.L.; Grigioni, F.; Schaff, H.V.; Tribouilloy, C.; Avierinos, J.F.; Barbieri, A.; Pasquet, A.; Huebner, M.; Rusinaru, D.; et al. Association between early surgical intervention vs watchful waiting and outcomes for mitral regurgitation due to flail mitral valve leaflets. JAMA 2013, 310, 609-616. [CrossRef] [PubMed]

23. Rosenhek, R.; Rader, F.; Klaar, U.; Gabriel, H.; Krejc, M.; Kalbeck, D.; Schemper, M.; Maurer, G.; Baumgartner, H. Outcome of watchful waiting in asymptomatic severe mitral regurgitation. Circulation 2006, 113, 2238-2244. [CrossRef] [PubMed]

24. Enriquez-Sarano, M.; Tajik, A.J.; Schaff, H.V.; Orszulak, T.A.; Bailey, K.R.; Frye, R.L. Echocardiographic prediction of survival after surgical correction of organic mitral regurgitation. Circulation 1994, 90, 830-837. [CrossRef]

25. Ponikowski, P.; Voors, A.A.; Anker, S.D.; Bueno, H.; Cleland, J.G.F.; Coats, A.J.S.; Falk, V.; González-Juanatey, J.R.; Harjola, V.; Jankowska, E.A.; et al. 2016 ESC Guidelines for the diagnosis and treatment of acute and chronic heart failure: The Task Force for the diagnosis and treatment of acute and chronic heart failure of the European Society of Cardiology (ESC). Developed with the special contribution of the Heart Failure Association (HFA) of the ESC. Eur. Heart J. 2016, 37, 2129-2200. [CrossRef]

26. van Bommel, R.J.; Marsan, N.A.; Delgado, V.; Borleffs, C.J.W.; van Rijnsoever, E.P.; Schalij, M.J.; Bax, J.J. Cardiac resynchronization therapy as a therapeutic option in patients with moderate-severe functional mitral regurgitation and high operative risk. Circulation 2011, 124, 912-919. [CrossRef]

27. Abraham, W.T.; Fisher, W.G.; Smith, A.L.; Delurgio, D.B.; Leon, A.R.; Loh, E.; Kocovic, D.Z.; Packer, M.; Clavell, A.L.; Hayes, D.L.; et al. Cardiac resynchronization in chronic heart failure. N. Engl. J. Med. 2002, 346, 1845-1853. [CrossRef]

28. Michler, R.E.; Smith, P.K.; Parides, M.K.; Ailawadi, G.; Thourani, V.; Moskowitz, A.J.; Acker, M.A.; Hung, J.W.; Chang, H.L.; Perrault, L.P.; et al. Two-year outcomes of surgical treatment of moderate ischemic mitral regurgitation. N. Engl. J. Med. 2016, 374, 1932-1941. [CrossRef]

29. Acker, M.A.; Parides, M.K.; Perrault, L.P.; Moskowitz, A.J.; Gelijns, A.C.; Voisine, P.; Smith, P.K.; Hung, J.W.; Blackstone, E.H.; Puskas, J.D.; et al. Mitral-valve repair versus replacement for severe ischemic mitral regurgitation. N. Engl. J. Med. 2014, 370, 23-32. [CrossRef]

30. Goldstein, D.; Moskowitz, A.J.; Gelijns, A.C.; Ailawadi, G.; Parides, M.K.; Perrault, L.P.; Hung, J.W.; Voisine, P.; Dagenais, F.; Gillinov, A.M.; et al. Two-year outcomes of surgical treatment of severe ischemic mitralregurgitation. N. Engl. J. Med. 2016, 374, 344-353. [CrossRef]

31. Suradi, H.S.; Kavinsky, C.J.; Hijazi, Z.M. Percutaneous mitral valve repair: The MitraClip device. Glob. Cardiol. Sci. Pract. 2016, 2016, e201617. [CrossRef] [PubMed]

32. Sherif, M.A.; Paranskaya, L.; Yuecel, S.; Kische, S.; Thiele, O.; D’Ancona, G.; Neuhausen-Abramkina, A.; Ortak, J.; Ince, H.; Öner, A. MitraClip step by step; how to simplify the procedure. Neth. Heart J. 2017, 25, 125-130. [CrossRef] [PubMed]

33. Feldman, T.; Kar, S.; Rinaldi, M.; Fail, P.; Hermiller, J.; Smalling, R.; Whitlow, P.L.; Gray, W.; Low, R.; Herrmann, H.C.; et al. Percutaneous mitral repair with the MitraClip system: Safety and midterm durability in the initial EVEREST (Endovascular Valve Edge-to-Edge REpair Study) cohort. J. Am. Coll. Cardiol. 2009, 54, 686-694. [CrossRef] [PubMed]

34. Attizzani, G.F.; Ohno, Y.; Capodanno, D.; Cannata, S.; Dipasqua, F.; Immé, S.; Mangiafico, S.; Barbanti, M.; Ministeri, M.; Cageggi, A.; et al. Extended use of percutaneous edge-to-edge mitral valve repairbeyond EVEREST (Endovascular Valve Edge-to-Edge Repair) criteria: 30- day and 12-month clinical and echocardiographic outcomes from the GRASP (Getting Reduction of Mitral Insufficiency by Percutaneous Clip Implantation) registry. JACC Cardiovasc. Interv. 2015, 8 PtA, 74-82. [CrossRef]

35. Lesevic, H.; Karl, M.; Braun, D.; Barthel, P.; Orban, M.; Pache, J.; Hadamitzky, M.; Mehilli, J.; Stecher, L.; Massberg, S.; et al. Longterm outcomes after MitraClip implantation according to the presence or absence of EVEREST inclusion criteria. Am. J. Cardiol. 2017, 119, 1255-1261. [CrossRef]

36. Feldman, T.; Foster, E.; Glower, D.D.; Kar, S.; Rinaldi, M.J.; Fail, P.S.; Smalling, R.W.; Siegel, R.; Rose, G.A.; Engeron, E.; et al. Percutaneous repair or surgery for mitral regurgitation. N. Engl. J. Med. 2011, 364, 1395-1406. [CrossRef]

37. Wan, B.; Rahnavardi, M.; Tian, D.H.; Phan, K.; Munkholm-Larsen, S.; Bannon, P.G.; Yan, T.D. A meta-analysis of MitraClip system versus surgery for treatment of severe mitral regurgitation. Ann. Cardiothorac. Surg. 2013, 2, 683-692. [CrossRef]

38. Pope, N.H.; Lim, S.; Ailawadi, G. Late calcific mitral stenosis after MitraClip procedure in a dialysis-dependent patient. Ann. Thorac. Surg. 2013, 95, e113-e114. [CrossRef]

39. Maisano, F.; Franzen, O.; Baldus, S.; Schäfer, U.; Hausleiter, J.; Butter, C.; Ussia, G.P.; Sievert, H.; Richardt, G.; Widder, J.D.; et al. Percutaneous mitral valve interventions in the real world: Early and 1-year results from the ACCESS-EU, a prospective, multicenter, nonrandomized post-approval study of the MitraClip therapy in Europe. J. Am. Coll. Cardiol. 2013, 62, 1052-1061. [CrossRef]

40. Stone, G.W.; Lindenfeld, J.; Abraham, W.T.; Kar, S.; Lim, D.S.; Mishell, J.M.; Whisenant, B.; Grayburn, P.A.; Rinaldi, M.; Kapadia, S.R.; et al. Transcatheter mitral-valve repair in patients with heart failure. N. Engl. J. Med. 2018, 379, 2307-2318. [CrossRef]

41. Obadia, J.F.; Messika-Zeitoun, D.; Leurent, G.; Iung, B.; Bonnet, G.; Piriou, N.; Lefèvre, T.; Piot, C.; Rouleau, F.; Carrié, D.; et al. Percutaneous repair or medical treatment for secondary mitral regurgitation. N. Engl. J. Med. 2018, 379, 2297-2306. [CrossRef]

42. Feldman, T.; Kar, S.; Elmariah, S.; Smart, S.C.; Trento, A.; Siegel, R.J.; Apruzzese, P.; Fail, P.; Rinaldi, M.J.; Smalling, R.W.; et al. Randomized comparison of percutaneous repair and surgery for mitralregurgitation: 5-year results of EVEREST II. J. Am. Coll. Cardiol. 2015, 66, 2844-2854. [CrossRef] [PubMed] 
43. Lim, D.S.; Reynolds, M.R.; Feldman, T.; Kar, S.; Herrmann, H.C.; Wang, A.; Whitlow, P.L.; Gray, W.A.; Grayburn, P.; Mack, M.J.; et al. Improved functional status and quality of life in prohibitive surgical risk patients with degenerative mitral regurgitation after transcatheter mitral valve repair. J. Am. Coll. Cardiol. 2014, 64, 182-192. [CrossRef] [PubMed]

44. Nishimura, R.A.; Bonow, R.O. Percutaneous repair of secondary mitral regurgitation-A tale of two trials. N. Engl. J. Med. 2018, 379, 2374-2376. [CrossRef] [PubMed]

45. Grayburn, P.A.; Sannino, A.; Packer, M. Proportionate and disproportionate functional mitral regurgitation: A new conceptual framework that reconciles the results of the MITRA-FR and COAPT trials. JACC Cardiovasc. Imaging 2019, 12, 353-362. [CrossRef] [PubMed]

46. Grayburn, P.A.; Carabello, B.; Hung, J.; Gillam, L.D.; Liang, D.; Mack, M.J.; McCarthy, P.M.; Miller, D.C.; Trento, A.; Siegel, R.J. Defining severe secondary mitral regurgitation:emphasizing an integrated approach. J. Am. Coll. Cardiol. 2014, 64, 2792-2801. [CrossRef]

47. Packer, M.; Grayburn, P.A. New Evidence Supporting a Novel Conceptual Framework for Distinguishing Proportionate and Disproportionate Functional Mitral Regurgitation. JAMA Cardiol. 2020, 5, 469-475. [CrossRef]

48. Messika-Zeitoun, D.; Iung, B.; Armoiry, X.; Trochu, J.N.; Donal, E.; Habib, G.; Brochet, E.; Thibault, H.; Piriou, N.; Cormier, B.; et al. Impact of Mitral Regurgitation Severity and Left Ventricular Remodeling on Outcome After Mitraclip Implantation: Results From the Mitra-FR Trial. JACC Cardiovasc. Imaging 2020. [CrossRef]

49. Grayburn, P.A.; Sannino, A.; Cohen, D.J.; Kar, S.; Lim, D.S.; Mishell, J.M.; Whisenant, B.K.; Rinaldi, M.J.; Kapadia, S.R.; Rajagopal, V.; et al. Predictors of Clinical Response to Transcatheter Reduction of Secondary Mitral Regurgitation: The COAPT Trial. J. Am. Coll. Cardiol. 2020, 76, 1007-1014. [CrossRef]

50. Grayburn, P.A.; Packer, M.; Sannino, A.; Stone, G.W. Disproportionate secondary mitral regurgitation: Myths, misconceptions and clinical implications. Heart 2020. [CrossRef]

51. Cavalcante, J.L.; Kusunose, K.; Obuchowski, N.A.; Jellis, C.; Griffin, B.P.; Flamm, S.D.; Kwon, D.H. Prognostic Impact of Ischemic Mitral Regurgitation Severity and Myocardial Infarct Quantification by Cardiovascular Magnetic Resonance. JACC Cardiovasc. Imaging 2020, 13, 1489-1501. [CrossRef] [PubMed]

52. Lim, D.S.; Kar, S.; Spargias, K.; Kipperman, R.M.; O’Neill, W.W.; Ng, M.K.; Fam, N.P.; Walters, D.L.; Webb, J.G.; Smith, R.L.; et al. Transcatheter Valve Repair for Patients With Mitral Regurgitation: 30-Day Results of the CLASP Study. JACC Cardiovasc. Interv. 2019, 12, 1369-1378. [CrossRef] [PubMed]

53. Sorajja, P.; Moat, N.; Badhwar, V.; Walters, D.; Paone, G.; Bethea, B.; Bae, R.; Dahle, G.; Mumtaz, M.; Grayburn, P.; et al. Initial Feasibility Study of a New Transcatheter Mitral Prosthesis: The First 100 Patients. J. Am. Coll. Cardiol. 2019, 73, 1250-1260. [CrossRef] [PubMed] 